\title{
PRODUÇÃO DE ADSORVENTES A PARTIR DE BIOMASSA DE EFLUENTES INDUSTRIAIS
}

\author{
J. J. BENEDET ${ }^{1}$, A. S. SCHEIBE ${ }^{1}$, T. W. LEAL $^{1}$, M. C. GONSALES ${ }^{1}$, S. M. A. GUELLI. U. \\ SOUZA $^{1}$ e A. A. ULSON DE SOUZA ${ }^{1}$ \\ ${ }^{1}$ Universidade Federal de Santa Catarina, Departamento de Engenharia Química e \\ Engenharia de Alimentos \\ E-mails para contato: jjbenedet@yahoo.com.br, augusto@enq.ufsc.br
}

\begin{abstract}
RESUMO - O estudo de novas rotas tecnológicas ambientalmente corretas se tornou alvo de várias pesquisas na literatura, visando adequar as atividades industriais à conscientização ambiental. Neste contexto, é apresentada neste trabalho a utilização do processo de adsorção de corantes de efluentes têxteis sintéticos, utilizando um adsorvente produzido a partir da biomassa de resíduos sólidos de efluentes industriais. O adsorvente é produzido por meio de pirólise, sendo a caracterização dos principais grupos funcionais presentes na superfície do adsorvente feita por análise de espectroscopia de Infravermelho com Transformada de Fourier (FT-IR). São apresentados os resultados da adsorção dos corantes reativos Procion Vermelho HE-7B ou RR 141. Os resultados comprovam que esta rota tecnológica é eficiente para a remoção dos corantes testados, muito frequentes nos efluentes da indústria têxtil.
\end{abstract}

\section{INTRODUÇÃO}

O setor têxtil, um dos mais importantes de Santa Catarina, é responsável por grande parte das atividades econômicas no estado. Entretanto, é também responsável por produzir efluentes compostos por diversos materiais poluentes, como os corantes utilizados na etapa de tingimento dos tecidos, causando problemas de contaminação ambiental. Estudos revelaram que a produção mundial de pigmentos e corantes sintéticos supera a marca de $7 \times 10^{5}$ toneladas por ano (Koprivanac e Kusic, 2008). Porém, durante os processos industriais nos quais são aplicados, cerca de 10 a $60 \%$ dos corantes reativos acabam sendo despejados no efluente (Hessel et al., 2007).

A lenta degradação biológica dos corantes e a coloração que liberam na água são fatores negativos que provocam efeitos nocivos ao meio ambiente, como o aumento da toxicidade e a alteração da absorção de luz. Além disso, esses produtos tóxicos também podem causar problemas de saúde a pessoas, quando em contato prolongado com os mesmos (Mckay; Sweeney, 1980; Silveira et al., 2011).

Algumas técnicas de remoção desses materiais aplicadas na indústria resultam da adição de compostos químicos ao efluente, aumentando a carga poluidora do sistema. Ou seja, apesar da existência de vários processos para o tratamento de efluentes líquidos, não há métodos suficientes capazes de remover os corantes das águas residuais de forma simples e adequada (Correia et al., 1994). 
Outro aspecto importante a ser considerado nos processos de degradação biológica é que a decomposição do material orgânico do efluente gerado é feita por bactérias, que se alimentam do mesmo e se reproduzem, gerando uma grande quantidade de biomassa, que resulta em um lodo. Este lodo também é um poluente, que depois de seco é destinado aos aterros industriais (Sonai, 2012).

Nesse contexto, a adsorção dos corantes é uma alternativa vantajosa, pois remove materiais poluentes que os processos biológicos convencionalmente não eliminam, além de não gerar componentes tóxicos ao meio ambiente (Longhinotti et al., 1998). A adsorção consiste na utilização de um adsorvente, que por meio da diferença de polaridade com o adsorbato, promove a ligação superficial entre os dois, removendo este do efluente.

O adsorvente mais utilizado no tratamento dos efluentes têxteis é o carvão ativado. Entretanto, a sua aplicação em escala industrial vem sendo reduzida devido ao seu alto custo, fator que proporciona espaço para estudos de desenvolvimento de materiais alternativos ao processo adsortivo (Vasques et al., 2011).

Diversas pesquisas já foram realizadas procurando encontrar materiais que possam promover a adsorção dos corantes têxteis de forma eficaz. Souza, Antunes e Conceição (2013) utilizaram a lama vermelha proveniente do refino da bauxita em indústrias de alumínio, obtendo resultados satisfatórios para aplicação industrial, mediante tratamentos térmico e químico e controle de pH. Lucena et al. (2013) estudaram a aplicação de soluções aquosas de quitosana na remoção de corantes e verificaram que a modificação deste composto com tioacetamida resultou no aumento na sua capacidade adsortiva. Furlan et al. (2010) aplicaram um adsorvente carbonoso (proveniente da casca de cocos) para a adsorção dos corantes, em um estudo acoplado aos processos de coagulação e floculação, resultando em uma associação eficiente ao tratamento de efluentes sintéticos da indústria têxtil. Adebayo et al. (2014) apresentaram estudos mais recentes da aplicação de lignina modificada quimicamente com alumínio e manganês no processo, para o qual também foram observados resultados positivos.

Entre mais exemplos de materiais estudados como adsorventes estão o ácido acrílico e a carboximetilcelulose (Zhang et al., 2014), alguns derivados agrícolas como a casca de arroz (Moreno, Figueroa e Hormaza, 2012), a humina (Jesus et al., 2011) e diversos outros, aplicados a diferentes corantes têxteis (adsorbato).

Nessa pesquisa, desenvolvida com base em estudos anteriores do grupo de pesquisa do LABMASSA/EQA/UFSC, utilizou-se o próprio resíduo da indústria têxtil como fonte de biomassa para a produção de adsorventes, por meio de um processo pirolítico (Vasques, 2008; Sonai, 2012; Vasques, 2012). Essa técnica consistiu em um tratamento físico do material com o intuito de aumentar a sua eficiência adsortiva. Após a ativação física, o produto ativado foi submetido a ensaios de adsorção, testes nos quais foram avaliados os melhores parâmetros para a remoção do corante do efluente, como pH e a variação da concentração de corante.

\section{MATERIAL E MÉTODOS}

Para a ativação física do adsorvente, foi desenvolvida uma metodologia baseada nos procedimentos contidos na patente INPI- RJ PI 0703182-3. O lodo do tratamento biológico in 
natura, foi obtido de uma indústria têxtil da região de Blumenau. Esse lodo, utilizado como biomassa, foi primeiramente seco ao sol, por $12 \mathrm{~h}$, peneirado e seco novamente em estufa. $\mathrm{O}$ adsorbato testado foi o corante reativo Procion Vermelho HE-7B (CI - Reactive Red 141 ou RR 141), fornecido pela mesma empresa.

Inicialmente, pesou-se uma quantidade do lodo in natura em um reator de aço inoxidável. $\mathrm{O}$ sistema foi colocado em uma mufla que permite o aquecimento a temperaturas até $800{ }^{\circ} \mathrm{C}$. Durante o processo, em um sistema fechado, o reator é conectado a um condensador, e este a um coletor que recebe o óleo pirolítico depositado. O coletor, por sua vez, é conectado a um manômetro em $\mathrm{U}$, e este a uma trompa de vácuo que remove o ar interno, impedindo a combustão do material. A Figura 1 apresenta o esquema descrito.

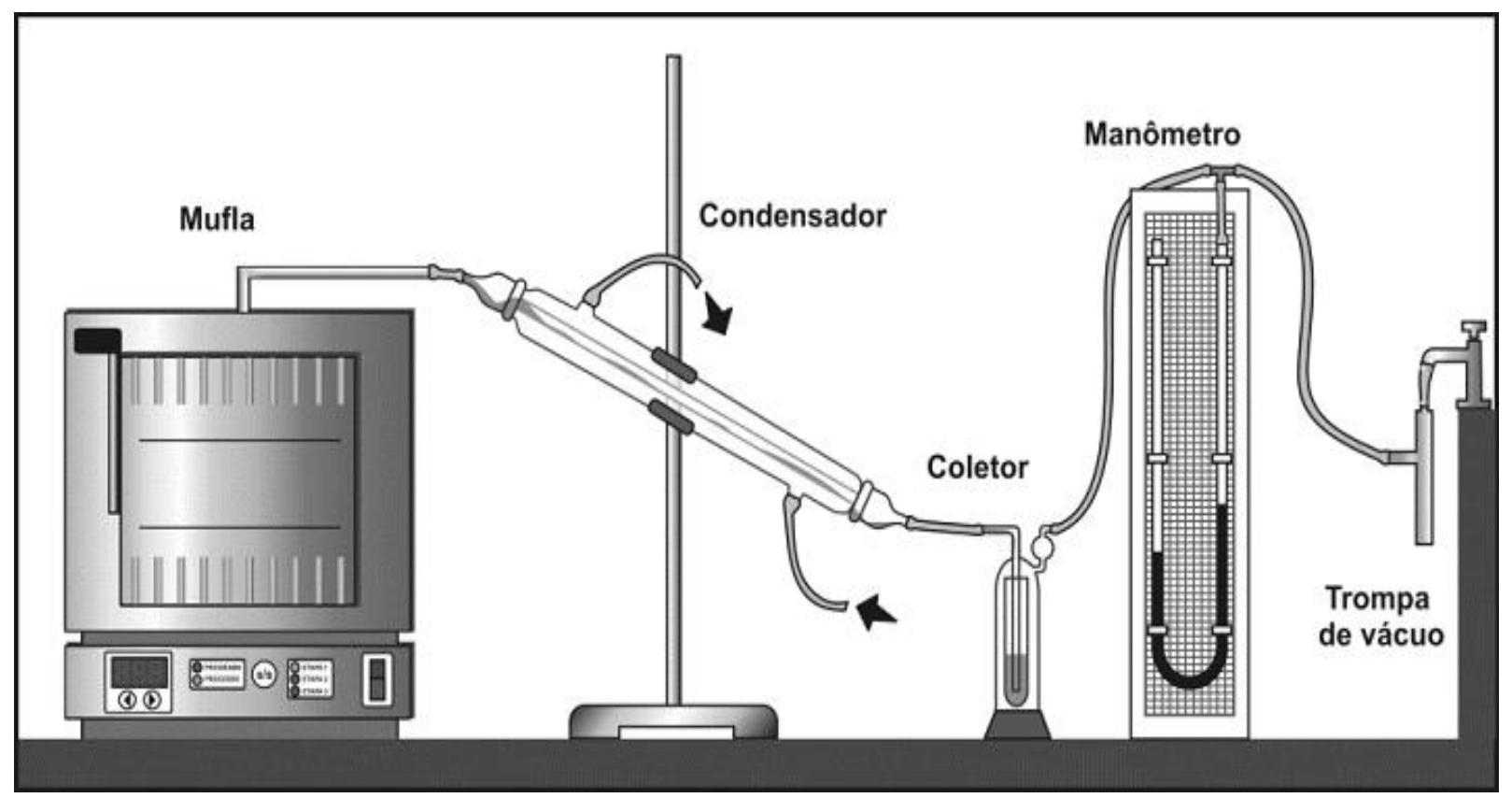

Figura 1 - Esquema do sistema empregado para o processo de pirólise.

Fonte: Sonai (2012).

Para a caracterização dos principais grupos funcionais presentes na superfície do lodo utilizou-se a análise de espectroscopia de Infravermelho com Transformada de Fourier (FT-IR), com medidas realizadas a uma resolução de $4 \mathrm{~cm}^{-1}$, nas frequências de 4000 a $400 \mathrm{~cm}^{-1}$. Previamente à análise, as amostras foram prensadas com brometo de potássio $(\mathrm{KBr})$, com o objetivo de formar uma pastilha. Os ensaios de FT-IR foram realizados tanto para o lodo in natura quanto para o lodo pirolisado (adsorvente).

Os ensaios de adsorção consistiram em testes realizados com tubos Falcon de $50 \mathrm{~mL}$ contendo soluções de 100 ou $500 \mathrm{mg} . \mathrm{L}^{-1}$ do corante, nos quais foram adicionados $0,5 \mathrm{~g}$ de adsorvente. $\mathrm{O} \mathrm{pH}$ das amostras foi ajustado para 4,0 ou 7,0, utilizando soluções $0,1 \mathrm{M}$ de ácido sulfúrico ou de hidróxido de sódio. Os tubos foram mantidos em agitação em um shaker horizontal por 4 h, a $200 \mathrm{rpm}$ e à temperatura ambiente. Após a agitação, uma alíquota das 
amostras foi retirada e analisada em espectrofotômetro UV-VIS, pela qual foi determinada a concentração final de corante presente na solução.

\section{RESULTADOS}

Por meio do gráfico fornecido pelo FT-IR de transmitância versus frequência, conforme mostra a Figura 2, foi possível verificar os grupos químicos presentes no lodo in natura e no pirolisado. A banda larga de adsorção entre 3000 e $3600 \mathrm{~cm}^{-1}$ corresponde aos estiramentos OH (fenóis, álcoois e grupos carboxílicos) e N-H (grupos aminos e amidos) e, também, assinala a presença de umidade (Gasco et al., 2007; Sonai, 2012). As bandas entre 2924 e $2914 \mathrm{~cm}^{-1}$ correspondem a estiramentos assimétricos de ligações $\mathrm{C}-\mathrm{H}$ alifáticas. Para o caso do lodo pirolisado, estas bandas desapareceram, uma vez que uma temperatura relativamente baixa é suficiente para quebrar estas ligações, o que promove a formação de gases contendo hidrocarbonetos, como metano e etano (Zhang et al., 2010). O mesmo desaparecimento é observado nos picos entre 1740 e $1620 \mathrm{~cm}^{-1}$, correspondentes ao estiramento $\mathrm{C}=\mathrm{O}$. Outras bandas que podem ser visualizadas são: em torno de $1550 \mathrm{~cm}^{-1}$, referentes a deformações angulares N-H de amidas; íons carboxilatos entre 1600 e $1590 \mathrm{~cm}^{-1}$ e em torno de $1400 \mathrm{~cm}^{-1}$; e deformações angulares de grupos C-O em torno de 1013 e $1095 \mathrm{~cm}^{-1}$, onde podem estar presentes compostos como éter, fenol, lactonas e ácidos carboxílicos (Sonai, 2012).

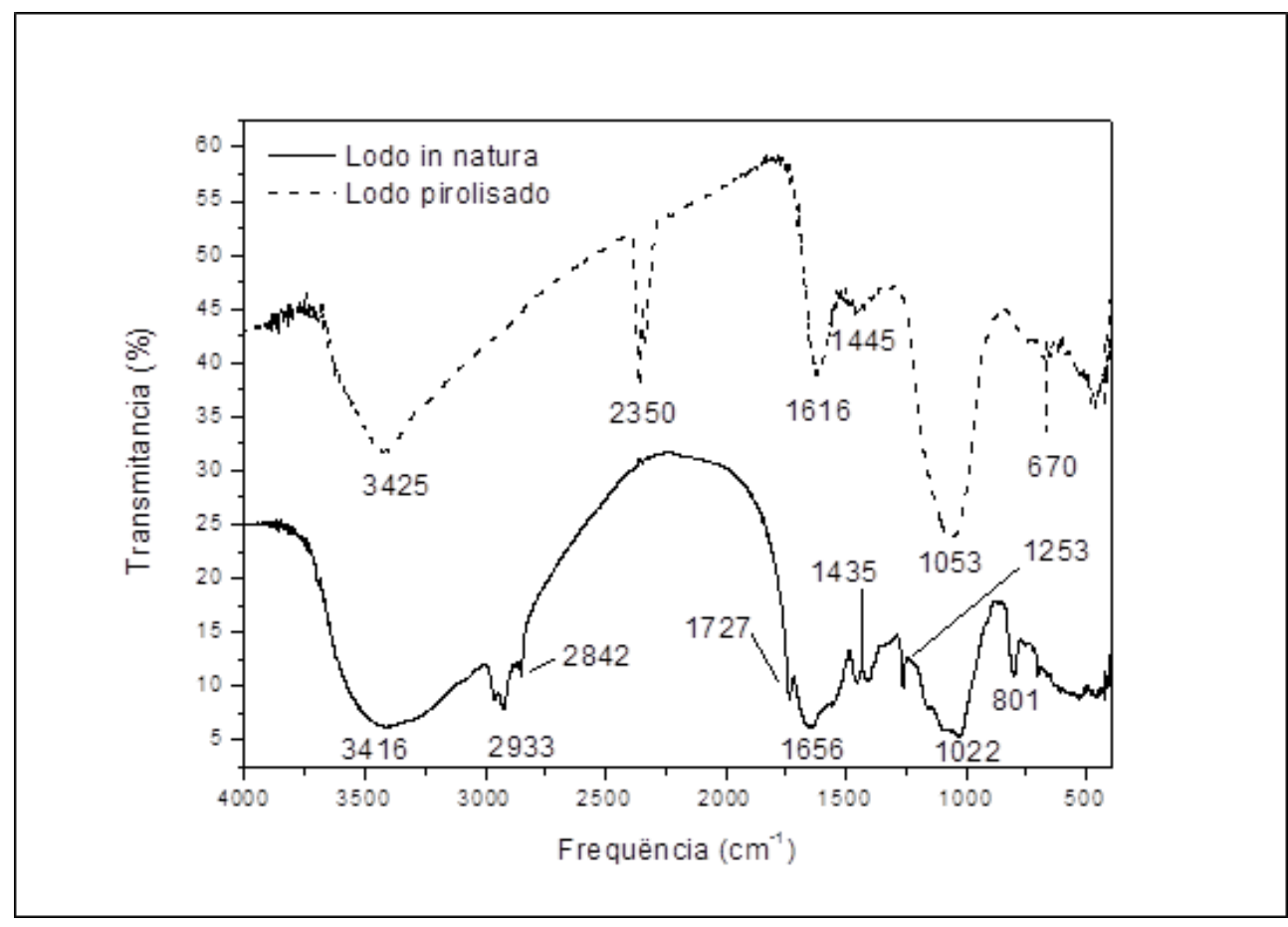

Figura 2 - Espectrograma do lodo in natura e do lodo pirolisado.

Com base nestes ensaios realizados após a pirólise, foi obtido o gráfico apresentado pela Figura 3, relacionando a variação do $\mathrm{pH}$ com a variação da concentração de corante, refletida na capacidade de adsorção. Analisando o gráfico, verificou-se que o aumento da concentração de corante acarretou no aumento da capacidade de adsorção do lodo. Além disso, observou-se 
que o pH não apresentou influência expressiva na adsorção do corante RR 141. De acordo com os resultados apresentados, verificou-se que o adsorvente produzido apresentou uma capacidade de adsorção entre 6,0 e $9,0 \mathrm{mg} / \mathrm{g}$ para o corante de concentração de $100 \mathrm{mg} / \mathrm{L}$, e entre 15,0 e $18,0 \mathrm{mg} / \mathrm{g}$ para as amostras de concentração de $500 \mathrm{mg} / \mathrm{L}$, conforme o pH ajustado das amostras.

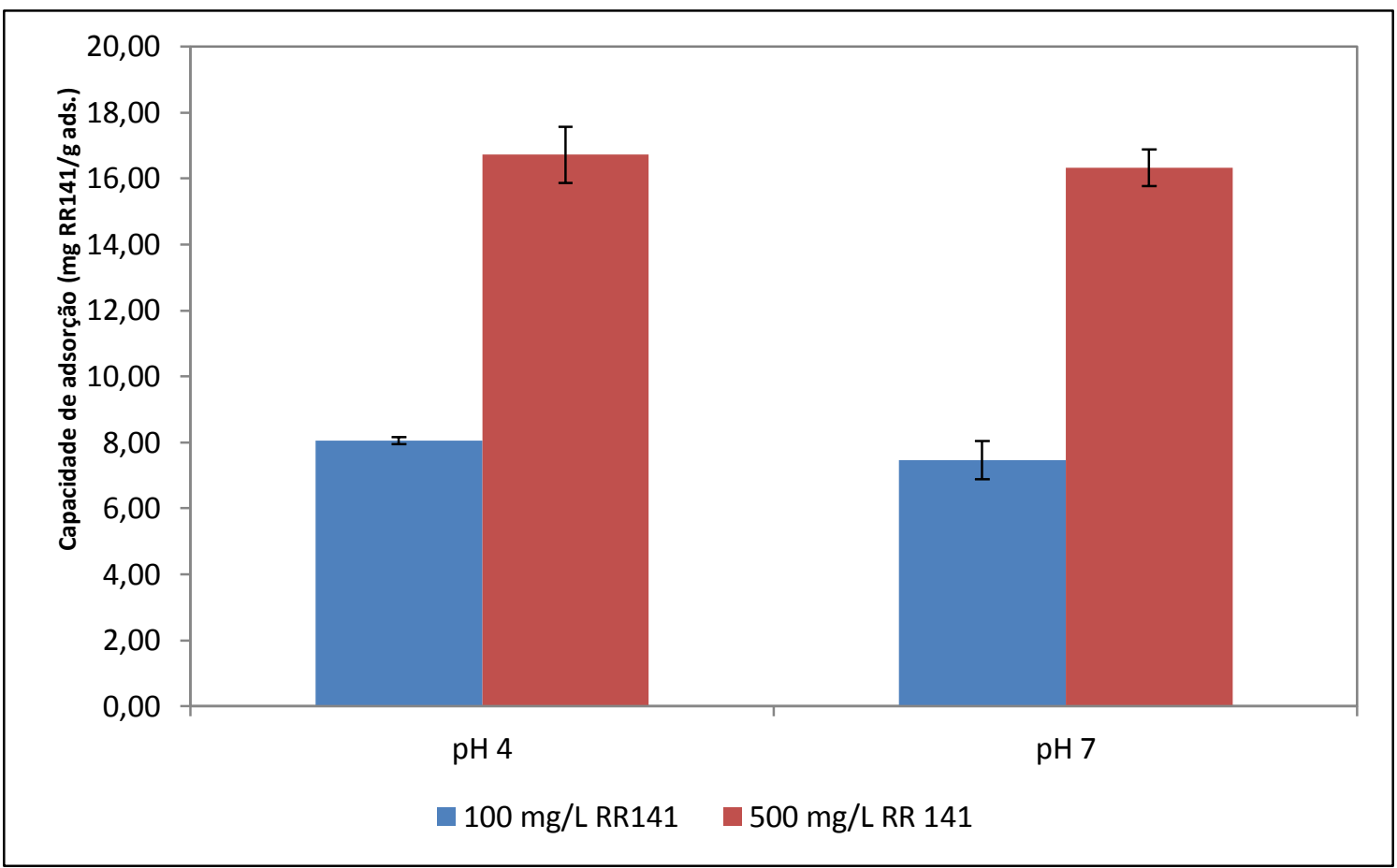

Figura 3 - Gráfico da variação da capacidade de adsorção em relação à variação do $\mathrm{pH}$.

\section{CONCLUSÃO}

A metodologia empregada para o tratamento físico do lodo, transformando-o em um adsorvente, apresentou resultados positivos à adsorção do corante RR 141. Outras metodologias ainda podem ser empregadas, alterando o procedimento, o adsorvente e/ou o corante, visando melhorias na eficiência de adsorção. Este procedimento pode ser utilizado em conjunto com outros processos de separação como membranas de nanofiltração, podendo ser um aliado no tratamento de efluentes e, consequentemente na preservação do meio ambiente.

\section{AGRADECIMENTOS}

Ao CNPq, pelo apoio na concessão de bolsa de pós-graduação. Ao BNDES, pelo apoio financeiro para a melhoria da infraestrutura laboratorial e concessão de bolsa de pesquisa.

\section{REFERÊNCIAS}


ADEBAYO, M. A.; PROLA, L. D. T.; LIMA, E. C.; PUCHANA-ROSERO, M. J.; CATALUÑA, R.; SAUCIER, C.; UMPIERRES, C. S.; VAGHETTI, J. C. P.; SILVA, L. G.; RUGGIERO, R. Adsorption of Procion Blue MX-R dye from aqueous solutions by lignin chemically modified with aluminium and manganese. J. Hazard. Mater., v. 268, p. 43-50, 2014.

CORREIA, V. M.; STEPHENSON, T.; JUDD, S. J., Characterization of Textile Wastewaters - A Review, Environ. Technology, v. 15, p. 917-929, 1994.

FURLAN, F. R.; SILVA, L. G. M.; MORGADO, A. F.; ULSON DE SOUZA, A. A.; GUELLI ULSON DE SOUZA, S. M. A. Removal of reactive dyes from aqueous solutions using combined coagulation/flocculation and adsorption on activated carbon. Resour., Conserv. Recy., v. 54, p. 283-290, 2010.

GASCO, G.; CUETO, M. J.; MÉNDEZ, A. The effect of acid treatment on the pyrolysis behavior of sewage sludges. J. Analyt. Appl. Pyrolysis, v. 80, n. 2, p. 96-501, 2007.

HESSEL, C.; ALlEGRE, C.; MAISSEU, M.; CHARBIT, F.; MOULIN, P. Guidelines and legislation for dye house effluents. J. Environ. Manage., v. 83, n. 2, p. 171-180, 2007.

JESUS, A. M. D.; ROMÃO, L.P.C.; ARAÚJO, B.R.; COSTA, A.S.; MARQUES, J. J. Use of humin as an alternative material for adsorption/desorption of reactive dyes. Desalination, v. 274, n. 1-3, p. 13-21, 2011.

KOPRIVANAC, N.; KUSIC, H. Hazardous organic pollutants in colored wastewaters. New York: New Science Publishers, 2008.

LONGHINOTTI, E.; POZZA, F.; FURLAN, L.; SANCHEZ, M. N. M.; KLUG, M.; LARANJEIRA, M. C. M.; FÁVERE, V. T. Adsorption of anionic dyes on the biopolymer chitin. J. Braz. Chem. Soc., v. 9, n. 5, p. 435-440, 1998.

LUCENA, G. L.; SILVA, A. G.; HONÓRIO, L. M. C.; SANTOS, V. D. Adsorção de corantes têxteis a partir de soluções aquosas por quitosana modificada com tioacetamida. Ambiente e Água, v. 8, n. 1, p. 144-154, 2013.

MCKAY, G.; SWEENEY, A. G. Principles of dye removal from textile effluent. Water Air Soil Pollut., v. 14, p. 3-11, 1980.

MORENO, A.; FIGUEROA, D.; HORMAZA, A. Adsorción de Azul de Metileno sobre cascarilla de arroz. Producción Más Limpia, v. 7, n. 1, p. 9-18, 2012.

SILVEIRA NETA, J. J.; MOREIRA, G. C.; SILVA, C. J.; REIS, C.; REIS, E. L. Use of polyurethane foams for the removal of the Direct Red 80 and Reactive Blue 21 dyes in aqueous medium. Desalination, v. 281, p. 55-60, 2011.

SONAI, G. G. Ativação de adsorventes carbonosos para a remoção de corantes de efluentes têxteis. Dissertação (Mestrado) - Universidade Federal de Santa Catarina, Florianópolis, 2012. 
SOUZA, K. C.; ANTUNES, M. L. P; CONCEIÇÃO, F. T. Adsorção do corante reativo azul 19 em solução aquosa por lama vermelha tratada quimicamente com peróxido de hidrogênio. Quím. Nova, v. 36, n. 5, p. 651-656, 2013.

ULSON de SOUZA, A. A.; GUELli U. SOUZA, S. M. A.; VASQUES, A. R.; VALLE, J. A. B. Composto adsorvente, processo para sua preparação e processo para tratamento de efluentes. Patente: Privilégio de Inovação. Número do registro: PI0703182, INPI 2007.

VASQUES, A. R. Caracterização e aplicação de adsorvente para remoção de corantes de efluentes têxteis em batelada e colunas de leito fixo. Dissertação (Mestrado) - Universidade Federal de Santa Catarina, 2008.

VASQUES, A. R. Caracterização de adsorventes obtidos por combustão e pirólise de lodo residual e aplicação no tratamento de efluentes têxteis. Tese (Doutorado em Engenharia Química) - Universidade Federal de Santa Catarina, Florianópolis, 2012.

VASQUES, A. R.; GUELLI U. SOUZA, S. M. A.; WEISSENBERG, L.; ULSON DE SOUZA, A. A.; VALLE, J. A. B., Adsorção dos corantes R016, RR2 e RR141 utilizando lodo residual na indústria têxtil. Eng. Sanit. Ambient., v. 16, n. 3, p. 245-252, 2011.

ZHANG, G.; YI, L.; DENG, H.; SUN, P. Dyes adsorption using a synthetic carboxymethyl cellulose-acrylic acid adsorbent. J. Environ. Sci., v. 26, n. 5, p. 1203-1211, 2014.

ZHANG, Q.; XING, H.; SUN, C.; XIANG, H.; JIANG, D.; QIN, L. The Mechanical Properties and Thermal Performances of Polypropylene with a Novel Intumescent Flame Retardant. J. Appl. Polym. Sci., v. 115, p. 2170-2177, 2010. 